\title{
A methodology for sustainable design analysis of large scale buildings
}

\author{
R. Richarde ${ }^{1} \&$ R. Ibrahim ${ }^{2}$ \\ ${ }^{I}$ Department of Architecture, California Polytechnic State University, \\ USA \\ ${ }^{2}$ Construction Engineering \& Management Program, \\ Stanford University, USA
}

\begin{abstract}
Long-term sustainability-including maintenance, operation, and life cycle cost analysis-should start during the concept design stage where most critical decisions are determined. This paper provides advice for owners, facility managers, and designers to optimize sustainable design options. Furthermore, by front ending the costs for implementing those design options, owners return on their investments are likely to be long term, they are likely to have reduced operational maintenance costs, and are likely to have an increase in global energy conservation. This paper proposes how to formalize a "Sustainable Methodology" (SM) to facilitate effective contributions by decision makers during the early concept design stage of a facility development project. The SM framework has five phases: input, evaluation, summarization, synthesizing, and output. These phases are initiated by the owner's preliminary architectural program and sustainable design goals, starting with site planning. The site planning elements are climate (macro- and micro-climate), orientation, use, function, shape/form, and surrounding (landscaping and buildings). The SM framework evaluates planning elements and suggests implementation options in harmony with environmental sustainability objectives.

In addition, this paper describes how the SM framework was tested on a multi-story mixed-use development project during its site planning. Further studies can extend the SM framework to include other aspects of facility design such as envelope, structure, services, and space planning.
\end{abstract}

Keywords: concepts, elements, phases, layers, components, scenario, strategy. 


\section{Introduction}

According to Knowles [1], given that a building has a forty years life span, the cost of the design process usually is about $10 \%$ of the initial budget cost, the cost of construction is $30-40 \%$ of that budget, and the remaining $60 \%$ is usually spent on maintenance and operations.

Large scale buildings contribute significantly to resource consumption, as well as to other environmental impacts, such as air emissions and solid waste generation and $17 \%$ of the total year-2000 US primary energy consumption [2]. Fossil fuel production has already peaked, and it is generally agreed that we are now in an era of declining oil production. With the resultant higher fuel costs, and the uncertainty surrounding energy sources, the need for energy conservation will be a key issue for making economic decisions. In particular, it is reasonable to assume that an objective of building design is to create the best possible facility for a given level of expenditure that utilizes the least amount of embodied and life cycle energy.

The objective during the initial development stage of a project should be to establish an effective set of design guidelines. Therefore, if a particular design constraint is essential to the proposed facility, such as incorporating sustainability issues, then the issues surrounding that constraint must be identified and provided to the designer prior to the initiation of building design. Fig. 1 shows in general terms the extent to which the influence of design decisions diminishes as the building project moves forward in time. Obviously, some degree of iteration occurs during all design and construction phases but the impact of design and construction changes decreases dramatically the closer the project moves to the bidding cycle. After bidding and during construction only minor changes can occur.

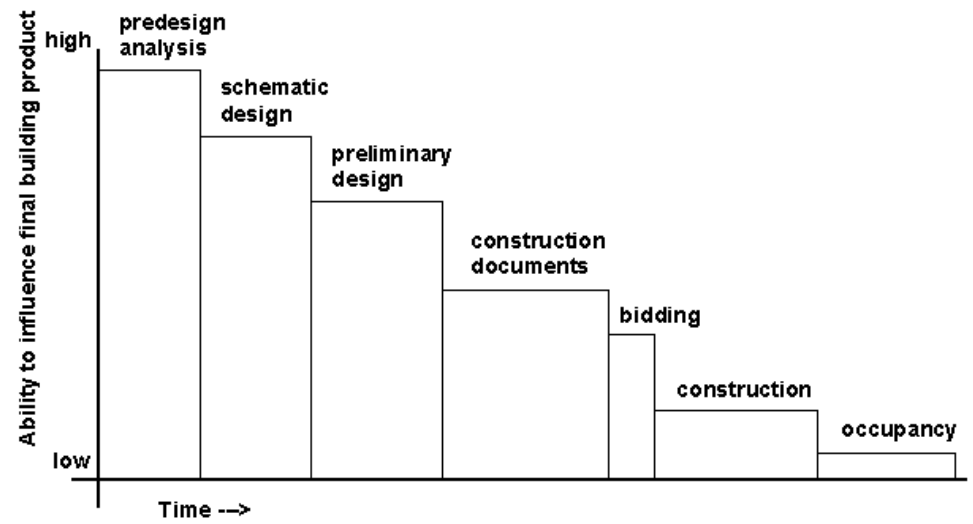

Figure 1: $\quad$ Time influence on design decisions. 
In order to demonstrate the importance of these design guidelines, this paper proposed an organization of a knowledge base "Sustainable Methodology" (SM) for dealing with the green design and sustainable principals. The primary concept is to provide design strategies directed to minimize future energy consumption and environmental impact. In addition, another reason for such organization is to simplify the way the design concepts are formed and generated.

This study uses Stewart's [3] model of concepts as a framework for evaluating various components of a building design. In this study, the paper builds upon a methodology using the five layers, with each layer called a concept, with elements representing different components. However, in application it suggests first to consider the site concept as the key to the successful use of the other concepts. Below are the five concepts and their elements, to be considered as tools for sustainable design in preliminary stage for multi-use building:

- Site: climate, orientation/solar access, shape/form, size, use, and function.

- Envelope: glazing, heat gain, heat loss, insulation, roof, energy efficiency, and apertures/windows, skylights, atriums.

- Structure: types, materials and its use, longevity, and recycled content vs. waste.

- Services: mechanical HVAC systems, electrical, pluming, lighting, passive heating and cooling.

- Space Plan (Interior): interior layout of floors, ceilings, walls, movable furnishings, and finishes.

\section{Overview of the Sustainable Methodology (SM)}

The SM is divided into five phases: Input, Evaluation, Summarizing, Synthesizing, and Output. Each phase provides data input for the succeeding phase, which eventually will provide the final recommendations for appropriate design options in the Output Phase, fig.2. Following is an overview for the five phases:

- Phase I - Input Phase: This phase identifies an owner's initial project idea. It introduces a preliminary architectural program at the pre-design phase that leads to prioritizing the owner's design goals in regards to sustainability. This process usually leads to identifying a specific site that may meet the above goals, and specific guidelines to consider for sustainable site development and evaluation.

- Phase II - Evaluation Phase: After a site has been selected, the evaluation of all available options for envelope, structure, services, and space planning elements follow. This evaluation is based on sustainable design options and the choice of the elements refers to the original sustainable design goals.

- Phase III - Summarizing Phase: This phase involves summarizing the evaluations of available options, and performing a prioritization process 
based on sustainable design goals. The product of this phase is a ranking of the options that were evaluated from Phase II.

- Phase IV - Synthesizing Phase: This phase involves using the most appropriate combined and ranked interchangeable elements from the Summary Phase, then identifying synergetic elements that enable optimized design and producing strategies for envelope, structure, services, and space planning concepts.

- Phase V - Output Phase: In this phase, the user selects the final strategies and produces formal sustainable design recommendations that are most appropriate to the client's goals and priorities.

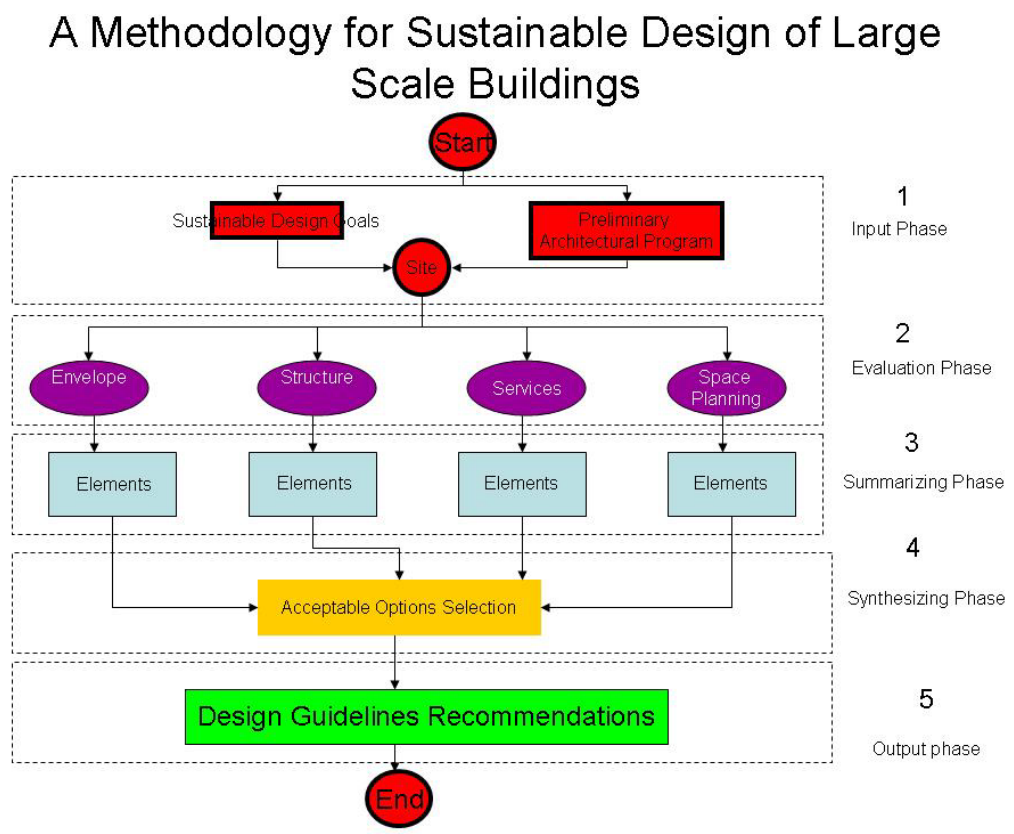

Figure 2: $\quad$ Overview of the SM Framework.

\section{The site concept}

The primary Site concept is measured, formalized, and tested because it is considered the basis on which a design will develop. The selection of the proper site and facility can make a valuable contribution to a project's profitability. Real estate costs are a business expense, and as such affect profit. Therefore, it is vital that real estate needs are carefully analyzed to determine what is needed and not needed in terms of, use of site, physical facility requirements, physical site requirements, and regional/local considerations. In order to optimize integrations with natural ecosystems, the SM site analysis will focus on the following site elements: climate, orientation, shape/form, size, use, function, and surroundings. 
When selecting a site, it is important to consider the impact on the community planning and the environment, such as contaminated sites, agricultural sites, and conservation of environmentally sensitive sites. The object of the site analysis is to guide the creation of the shape, structure, geometry, and scale of the building so that it can maintain equilibrium under the stress of the cyclic changes of nature (seasons change, precipitation, insolation, etc.). In addition, when site elements are considered and evaluated, the site analysis will guide the conception of a building of multiple components, including envelope, structure, services, and space planning, which determine the building longevity, life cycle, maintenance, and operations. Furthermore, each one of those site elements enables the selection of appropriate components. For example, once a site location and climate consideration with solar access is identified, then form and orientation can be established, which then lead to use and function, fig. 3.

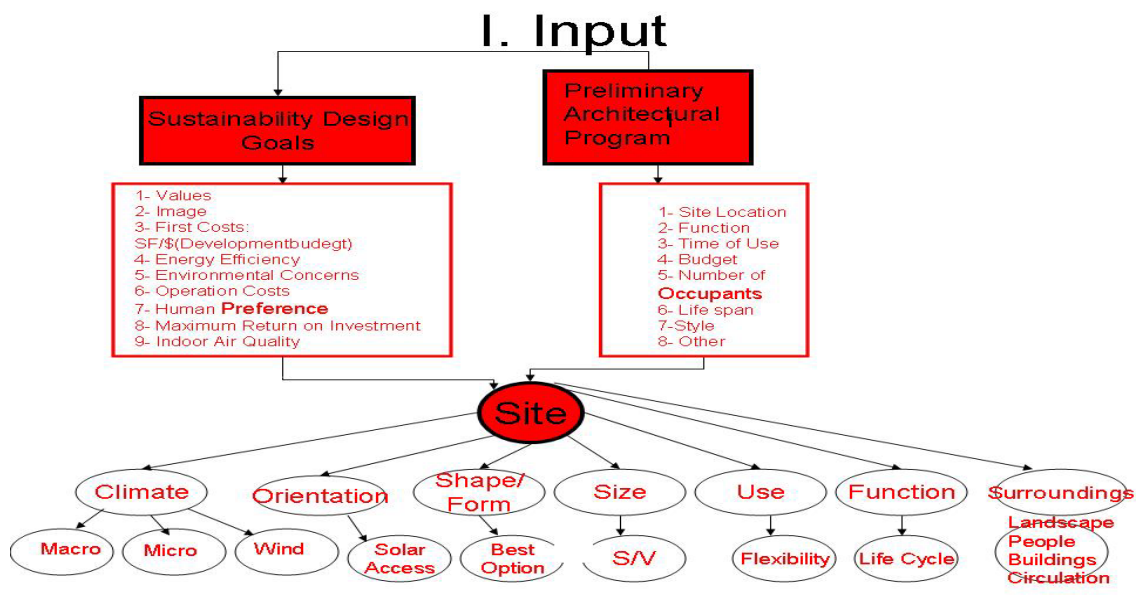

Figure 3: Overview of sustainable methodology.

\section{Case study}

This paper investigates the decision process and key criteria owners and facility planners use to assess the pre-design phase, when given a preliminary program and a set of design goals. The proposed sustainable methodology (SM) for predesign analysis of large scale buildings is tested at a student housing project at one of the CalPoly campuses in Central California. The SM case study provides advice to minimize environmental impact, increase energy conservation and resource efficiency, and reduce cost over the life cycle of the project.

\subsection{Background}

The CalPoly student housing project will provide apartment units, parking and a village centre with recreation and retail facilities for 2,700 students. The project will be comprised of 902 one, two and four-bedroom apartments and adjoining 
2,000 parking spaces. This will be the largest student housing project ever built on a public California university campus.

\subsubsection{Research methodology}

This research is a case study research that has the following three objectives. First, to map out the decision process that occurred during the pre-design phase of SHN; second, to identify points in the decision making process where the SM can be useful; and third, to attempt to use the SM at those points and reinterpret the results as if the questions in the SM were seriously applied. The first author interviewed seven of the major space planning decision makers that had authority over the development of the CalPoly student housing project. The data of each interview were entered in a table that presented thirteen questions and answers. The results were defined by comparing the responses and by looking for internal contradictions and consistencies. Then a strategy was developed based on the client's goals and priorities for the project, as well as the interviewer's responses and comment (Transcribed Interviews). Finally, an assessment was made on how that strategy, fits into the proposed SM.

\subsection{Recommendations}

\subsubsection{Identification of SM intervention}

There is a significant difference between the client's early design process and goals, and the SM. The client's priorities emphasized barbecues and attractive design versus those of SM, which emphasized human preference and energy efficiency. As shown in fig.4, when the SM was inserted in the pre-design process of the housing project, it had the potential to provide an improved process and improved results.

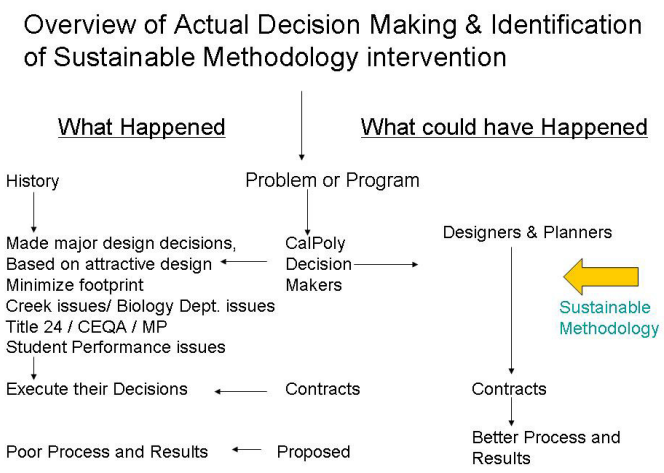

Figure 4: Identification of SM intervention.

\subsubsection{Orientation}

After careful review of the project's site plan, it has been shown through light studies and solar analysis that the orientation of this development is rather poor. 
According to Haggard and Niles [4], cost savings of about 70\% might occur with proper calculations for building orientation and thermal mass. In order to achieve such savings the following are the guidelines for natural heating and cooling:

- Building oriented toward the equator with a maximum deviation allowed of + or -20 degrees.

- $\quad 12$ to $20 \%$ of floor area in south glass.

- If low e glass is used it must be receiving low e Hard coat ( $\mathrm{U}>.33$ and solar heat gain coefficient $>.65$ ) for the south window.

- This south glass should be shared by approximately a 2'-6" overhang to allow summer shading while allowing winter sun in.

- Provide 10 square feet of any combination of the following thermal mass options for each square foot of south glass:

- Interior masonry wall 2 inches or more in thickness.

- Exposed concrete floor slab with a non insulting finish such as plain or colored concrete, tile, or directly applied wood or bamboo parquet.

- 9 inch thick water tank directly exposed to the south light in the winter.

- Double $5 / 8$ inch thick drywall counts one-half.

- Ability to cross ventilate all major rooms at night with at least 4 square feet of opening on two sides per 100 square feet of floor area in order to cool the thermal mass in the summer.

The above proposed $70 \%$ cost savings would make economic sense with 2,700 residents. Another advantage to proper solar orientation comes from reduced heat gains. Less heat entering the building envelope reduces the need for cooling. Natural light also reduces the need for artificial lighting, therefore it is proposed by the same report and guidelines mentioned above to have windows, skylight, or roof light tube within at least 15 feet of each other. In addition, to have all the major spaces must have natural light from two different directions.

\subsubsection{Climate}

The climate analysis for the housing project's location, fig.5, was based on a spreadsheet by Pena [5]. The spreadsheet creates a matrix of temperatures for the year, giving the average temperatures for two-hour intervals for each month. The spreadsheet allows a user to input temperature data, the average high and low temperature for each month, and uses these data to estimate the temperature for two-hour intervals between these high and low temperatures. The temperatures which are colored in, indicating the closed heating mode in winter, open "sailing" (no mechanical systems in operation) in spring and fall, and closed cooling periods in summer, based on assumptions for a building that has a balance point temperature of 55 degrees and a closed cooling temperature of 75 degrees. The average percent of the yellow area is $10 \%$, blue is $45 \%$, and white is $45 \%$. This concludes that the climate in Central Coast area of California allows the buildings to operate without any mechanical systems almost 50-60\% of the times in terms of cooling and heating. 


\begin{tabular}{|c|c|c|c|c|c|c|c|c|c|c|c|c|}
\hline & JAN & FEB & MAR & APR & MAY & JUN & JUL & AUG & SEP & OCT & NOV & DEC \\
\hline 12 midnight & 46 & 48 & 49 & 51 & 53 & 56 & 58 & 59 & 58 & 56 & 51 & 47 \\
\hline 2 & 45 & 46 & 47 & 49 & 51 & 54 & 56 & 56 & 56 & 54 & 49 & 45 \\
\hline 4 & 43 & 45 & 45 & 47 & 49 & 52 & 54 & 54 & 54 & 52 & 47 & 43 \\
\hline 6 & 42 & 43 & 44 & 46 & 48 & 50 & 52 & 53 & 53 & 50 & 46 & 42 \\
\hline 8 & 44 & 46 & 46 & 48 & 50 & 53 & 55 & 56 & 55 & 53 & 49 & 45 \\
\hline 12 noon & 50 & 62 & 62 & 65 & 67 & 71 & 75 & 76 & 75 & 73 & 67 & 61 \\
\hline 2 & 63 & 65 & 65 & 68 & 70 & 75 & 78 & 79 & 79 & 77 & 71 & 65 \\
\hline 4 & 61 & 63 & 64 & 66 & 68 & 73 & 76 & 77 & 77 & 74 & 68 & 63 \\
\hline 6 & 56 & 58 & 59 & 61 & 63 & 67 & 70 & 71 & 71 & 68 & 63 & 58 \\
\hline 8 & 51 & 53 & 53 & 56 & 58 & 61 & 64 & 65 & 64 & 62 & 57 & 52 \\
\hline 10 & 48 & 50 & 50 & 53 & 55 & 58 & 60 & 61 & 61 & 58 & 53 & 49 \\
\hline
\end{tabular}

Figure 5: Climate analysis.

\subsubsection{Circulation}

Parking and a consequence of it, vehicular circulation are the main factors in energy use and pollution, per the San Luis Obispo Air Pollution Control District. In many cases, circulation contributes more to environmental degradation than inadequate building orientation. Circulation choices - e.g., the availability of attractive non-motorized modes (such as bicycling, pedestrian roads, and public transportation) - also enhance social equity.

The university project's Environmental Impact Report executed in summer of 2003 , does not primarily think of alternative transportation or a shuttle bus but emphasizes an abundance of wide roads. The proposed alternative would enhance a non-motorized transportation and allows for a direct shuttle bus from the housing project to the Campus Market, campus core, and points further south. Pedestrian and bicycle paths, fully separated from roads, are proposed. This solution can easily be developed in phases, where the first phase is much less expensive than the current road concept.

\subsubsection{Parking}

The university housing project's site plans have proposed two main parking structures; one is at the north side of the site and the other at the south side of the site. For 2,700 beds, a full 2,000 parking spaces are now being designed, which means 0.7 parking spaces per bed. It is proposed, a first phase of 300 spaces would be ample; if demand exists, more spaces could be built later. Furthermore, this research proposes to create a single parking structure with three levels of 60,000 square feet each, for a total of 670 spaces at a ratio of 0.25 spaces per bed. The structure will be located uphill from the SHN development, partially underground (cut into the hillside) to avoid blocking views or creating an eyesore. It will be accessible from the one-way perimeter road around the complex. If this structure were to embrace the contours of the hill of the north side, then a solar roof could be devised to capture energy, shade the cars, and produce electricity for night-time street and parking structure lighting. 
Eventually, electricity may be used locally or sold back to Pacific Gas \& Electricity for net metering, and the power may be used to charge a fleet of electric vehicles, which would encourage the use of electric cars around the campus and reduce pollution and the use of fossil fuel (energy efficiency).

\section{Conclusions}

The SM for sustainable design was developed to help owners, facility managers, and designers contribute effectively during the pre-design analysis stage where most decisions are determined for the performance and life cycle of the building. It was concluded that by adopting this pre-design SM tool, positive financial profits may be generated throughout the building's life cycle, in particular through a reduction in its operations and maintenance costs. Furthermore, the framework was successfully tested on a large-scale public California university housing project development during the pre-design analysis stage of the site. It was quite difficult to perform the pre-design analysis prior to the official expiration deadlines of the grants and funds because of many politics and bureaucracy restrictions. When comparing the CalPoly process and the SM process, this research concluded that if the university's system had used the SM, it would have saved the decision-makers time and unneeded battles between the campus planning committee and the facility planers and developer. In addition, it would have provided the opportunity to design and rethink the traditional designs, using sustainable alternatives. This research proposes that this SM be tested on more campus projects and non-campus facilities (corporates, health care, schools, etc.) this will further enable the determination of the measure of success of the methodology at the pre-design phase. The SM framework could be used to evaluate other building design components, such as envelope, structure, services, and space planning. Future studies could enhance the SM in allowing owners to evaluate the design options before committing to a site.

Finally, there is a need for a further development of the SM framework into a computational tool to provide more detailed project guidelines and recommendations. This study has defined the groundwork for more implementation of sustainable design. This may help professionals who are not as familiar with sustainable design principles and an easy way to add sustainable elements into their building designs.

\section{References}

[1] Knowles, R., Energy and Form, MIT: Cambridge, 1974.

[2] US Green Building Council. Leadership in Energy \& Environmental Design, Rating System V.2.1. Washington: USGBC, 2002. www.usgbc.org.

[3] Brand, S., How Buildings Learn, Penguin: New York, 1995.

[4] Haggard, K. \& Niles, R., Passive Solar Hand Book, California: State Energy Commission, 1980. 
194 Eco-Architecture: Harmonisation between Architecture and Nature

[5] Pena, R. Personal communication, 23 January 2005, Professor of Architecture, California Polytechnic Institute, San Luis Obispo, California, USA. 